\title{
Antibacterials Developed to Target a Single Organism: Mechanisms and Frequencies of Reduced Susceptibility to the Novel Anti-Clostridium difficile Compounds Fidaxomicin and LFF571
}

\author{
Jennifer A. Leeds \\ Infectious Disease Area, Novartis Institutes for BioMedical Research, Emeryville, California 94608 \\ Correspondence: jennifer.leeds@novartis.com
}

Clostridium difficile is the most common cause of antibacterial-associated diarrhea. Clear clinical presentation and rapid diagnostics enable targeted therapy for $C$. difficile infection (CDI) to start quickly. CDI treatment includes metronidazole and vancomycin (VAN). Despite decades of use for CDI, no clinically meaningful resistance to either agent has emerged. Fidaxomicin (FDX), an RNA polymerase inhibitor, is also approved to treat CDI. Mutants with reduced susceptibility to FDX have been selected in vitro by single and multistep methods. Strains with elevated FDX minimum inhibitory concentrations (MICs) were also identified from FDX-treated patients in clinical trials. LFF571 is an exploratory agent that inhibits EF-Tu. In a proof-of-concept study, LFF571 was safe and effective for treating CDI. Spontaneous mutants with reduced susceptibility to LFF571 were selected in vitro in a single step, but not via serial passage. Although there are several agents in development for treatment of CDI, this review summarizes the frequencies and mechanisms of $C$. difficile mutants displaying reduced susceptibility to FDX or LFF71.

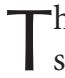
herapy for a suspected infection is often started empirically, based on the most likely syndrome and local epidemiological data well before the causative organism is identified. Because many clinical syndromes can be caused by a number of different pathogens, singly or in combination, the initial empiric therapy of severe infection is selected to cover the most likely organisms; this often involves broad-spectrum coverage to ensure that the condition of the patient does not worsen while the precise etiology is being determined microbiologically. However, in some circumstances, a physician can narrow the list of potential pathogens quickly and choose an initial therapy that is more organism specific. One of those indications is antibioticassociated diarrhea, in which the leading cause is infection with $C$. difficile and rapid diagnostics can quickly identify whether it is likely to be the pathogen.

Clostridium difficile infection (CDI) can cause mild to severe intestinal disease (Cohen

Editors: Lynn L. Silver and Karen Bush

Additional Perspectives on Antibiotics and Antibiotic Resistance available at www.perspectivesinmedicine.org

Copyright (C) 2016 Cold Spring Harbor Laboratory Press; all rights reserved; doi: 10.1101/cshperspect.a025445

Cite this article as Cold Spring Harb Perspect Med 2016;6:a025445 
J.A. Leeds

et al. 2010). A recently published survey of hospital inpatients from geographically diverse sites in the United States indicated that $C$. difficile was the most commonly reported nosocomial pathogen, and was the cause of $12.1 \%$ of health care-related infections in the institutions studied (Magill et al. 2014). The ability of $C$. difficile to form spores makes it difficult to remove from surfaces and allows it to spread easily and quickly within a health care setting. Over the past decade, the incidence of $C$. difficile infection has increased, and hypervirulent strains, such as B1/NAP1/027, have become more prevalent (McDonald et al. 2005). The epidemiology of CDI is also changing, as the disease is now more commonly seen outside the hospital environment and in some patients with no obvious underlying risk factors, compared with what was observed historically (Hensgens et al. 2014; Evans and Safdar 2015; Lessa et al. 2015).

Because the major risks for acquiring CDI are well defined, those, in combination with the clear clinical presentation and the availability of relatively rapid and accurate diagnostic tools for identifying toxigenic $C$. difficile (reviewed in Bagdasarian et al. 2015), allow for a presumptive diagnosis to be made quite confidently within a few hours following the onset of symptoms with appropriate therapy started quickly, and a definitive diagnosis can be made within a day or two, depending on the testing algorithm applied. The current guidelines for diagnosis and treatment of CDI (Cohen et al. 2010; Debast et al. 2014), depending on disease severity and number or risk of recurrences, include the generic antibiotics vancomycin and metronidazole, the former of which is active against Gram-positive bacteria only, and the latter having activity limited to obligate anaerobes (Baxter Healthcare Corp. Metronidazole Injection, UST RTU Product Insert, Deerfield, IL, 2009 [www.accessdata.fda .gov/drugsatfda_docs/label/2009/018657s029lbl .pdf ]; and Baxter Healthcare Corp. Vancomycin Injection, USP Product Insert, Deerfield, IL, 2011 [www.accessdata.fda.gov/drugsatfda_docs/ label/2012/050671s018lbl.pdf ]). The antibacterial actions of these agents are owing to inhibition of functions that are essential to bacterial growth and survival, and the molecular target(s) of these antibacterials are synthesized from more than one gene product (reviewed in Healy et al. 2000). This multigene/target feature coincides with the observation that there are no reports of single-step spontaneous mutations in $C$. difficile that confer high-level clinically relevant loss of susceptibility to either agent. Recently, a pan-European survey of C. difficile isolates from 2011 to 2012 showed $>96 \%$ susceptibility to vancomycin and metronidazole, despite many decades of use of these agents to treat $C$. difficile infection (Freeman et al. 2015). Accordingly, there is little compelling clinical data from adequately powered and controlled studies to indicate that treatment failure for $\mathrm{CDI}$ is owing to antimicrobial resistance to either of these agents, and there are no breakpoints or routine susceptibility testing used to guide the choice of treatment for CDI (Bauer et al. 2009; Cohen et al. 2010; Debast et al. 2014). Unfortunately, recurrent disease occurs in $\sim 20 \%-25 \%$ of patients whose symptoms resolved following treatment with VAN and MET (reviewed in Debast et al. 2014). As such, current clinical development programs monitor the impact of exploratory interventions on the rate of CDI recurrence following initial clinical cure.

In 2011, the first drug from a new class of antibacterials, fidaxomicin (FDX), was approved by the U.S. Food and Drug Administration (FDA) for the treatment of C. difficileassociated diarrhea in adults $\geq 18$ years of age (Optimer Pharmaceuticals, Dificid Package Insert, San Diego, CA, 2011 [www.accessdata.fda .gov/drugsatfda_docs/label/2011/201699s000 lbl.pdf]). Marketing authorization followed shortly thereafter throughout the European Union, Japan, Australia, and Canada. Based on data from two phase III trials, FDX is also recommended, with moderate evidence, by the European Society of Clinical Microbiology and Infectious Diseases (ESCMID) as an alternative to vancomycin when patients are at risk of first recurrence or have had multiple recurrences (Debast et al. 2014). Infectious Disease Society of America (IDSA) has not yet updated its guidance to include FDX (Cohen et al. 2010); however, clinical practice advisory groups have published recommendations for its use (Surawicz et al. 2013). FDX inhibits the growth 
of C. difficile, and other susceptible organisms, via inhibition of the clinically validated target bacterial RNA polymerase (Coronelli et al. 1975). The mechanism of inhibition and the predicted binding site for FDX on RNA polymerase (RNAP) is distinct from that of the rifamycins (reviewed in Srivastava et al. 2011) and there is no cross-resistance between FDX and the clinically used agents from this drug class (Goldstein et al. 2011).

There are multiple exploratory compounds with excellent in vitro potency against $C$. difficile, some of which have entered clinical development and have shown efficacy in patients with CDI (reviewed recently in Tsutsumi et al. 2014 and Ivarsson et al. 2015). Several of the antibacterials in clinical trials for treatment of CDI, including surotomycin and cadezolid, are derivatives of clinically used drugs (daptomycin and fluoroquinolones/oxazolidinones, respectively) and are inhibitors of clinically validated molecular targets (Locher et al. 2014b; Yin et al. 2015). LFF571 is an exploratory anti-C. difficile compound that has shown safety and efficacy in a phase II trial in humans for treatment of mild to moderate $C$. difficile infection (Mullane et al. 2015); however, LFF571 is derived from a novel scaffold that is not in clinical use and inhibits a molecular target, elongation factor $\mathrm{Tu}$, that is also clinically unprecedented (LaMarche et al. 2012; Leeds et al. 2012).

LFF571 and FDX both interfere with the growth of $C$. difficile by inhibiting essential pathways that involve large, multimolecular complexes; however, because the molecular mechanisms by which they inhibit their respective targets can be interrupted by single amino acid substitutions within single-gene products, both are subject to reduction in antibacterial potency via selection for spontaneous, singlestep mutants.

This review will summarize the mechanisms of action and review the literature reports of the frequencies and mechanisms of reduced susceptibility to FDX and LFF571. These agents exemplify relatively narrowly focused therapeutics in that, although both show antibacterial activity in vitro against a range of Gram-positive species, they have both been studied in humans
Resistance of C. difficile to Fidaxomicin and LFF571

exclusively against $C$. difficile because of their remarkable potency against this pathogen (minimum inhibitory concentrations [MICs $]_{90}$ $\leq 0.5 \mu / \mathrm{mL}$ ) (Citron et al. 2012; Goldstein et al. 2012; Hecht and Gerding 2012; Debast et al. 2013) and because their physicochemical properties result in the ability to achieve high drug concentrations in the target organ (colon) with very little systemic exposure (Sears et al. 2012; Ting et al. 2012; Bhansali et al. 2015).

\section{ANTIMICROBIAL MECHANISM OF ACTION OF FDX}

FDX is an 18 -membered macrocyclic natural bacterial fermentation product that is identical in structure to lipiarmycin A3, tiacumicin B, and clostimicin B1 (Fig. 1) (Omura et al. 1986; Theriault et al. 1987; Bedeschi et al. 2014). For simplicity, this review will refer to this structure only as "fidaxomicin." Published reports of the isolation of this chemical structure and the description of its mechanism of action dates back to 1975 (Coronelli et al. 1975). Macromolecular synthesis inhibition assays indicated that the mechanism of antimicrobial action of FDX was via rapid inhibition of RNA synthesis, which led to an almost simultaneous loss of protein synthesis (Coronelli et al. 1975; Sergio et al. 1975). However, the drug does not inhibit the translation machinery directly and only inhibits protein synthesis as a result of inhibition of transcription via binding to RNA polymerase (Sergio et al. 1975). FDX inhibits the very early steps in initiation of RNA synthesis, before the formation of a stable open complex, but does not inhibit elongation by RNAP (Sergio et al. 1975; Artsimovitch et al. 2012). Based on mapping of residues conferring loss of susceptibility to FDX, the drug is thought to bind portions of the $\beta$ - and $\beta^{\prime}$-subunits found in the RNA exit channel of RNAP and part of the switch region, including parts of switch 2 and switch 3 of the RNA polymerase (Srivastava et al. 2011; Artsimovitch et al. 2012).

Although FDX inhibits the function of RNAP from Gram-positive and Gram-negative organisms (Coronelli et al. 1975; Sergio et al. 1975; Sonenshein et al. 1977), it is active in vitro 
J.A. Leeds

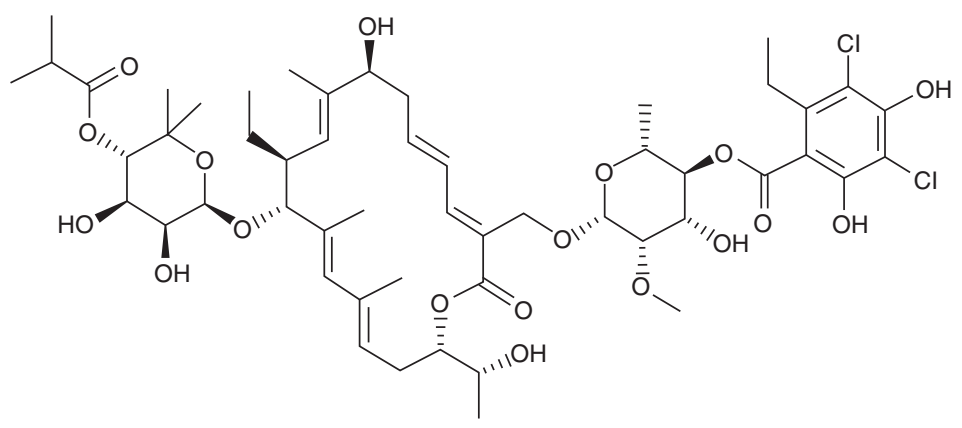

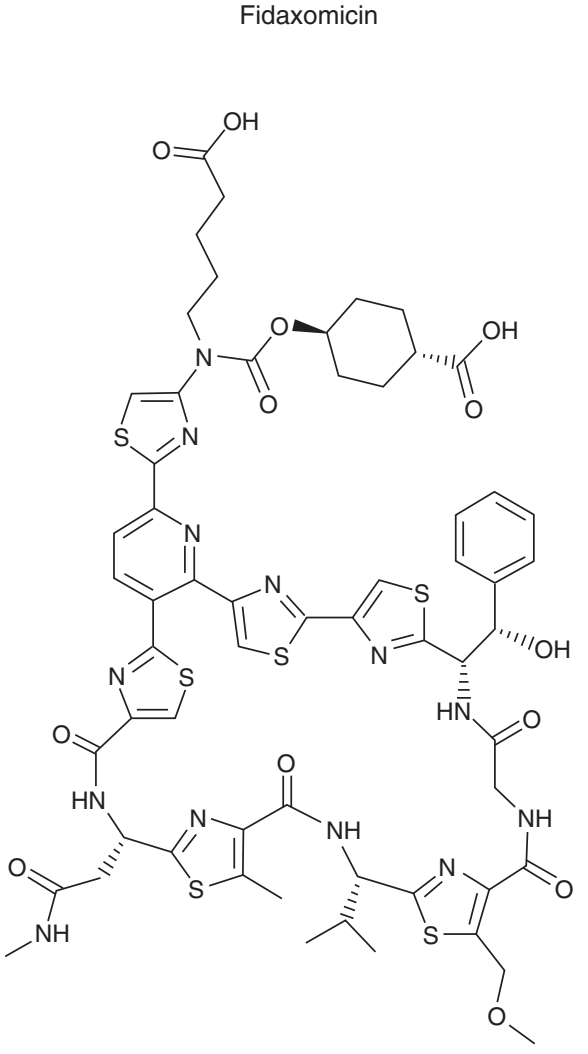

LFF571

Figure 1. Chemical structures of fidaxomicin (FDX) and LFF571.

against only a limited range of Gram-positive aerobes and anaerobes, including $C$. difficile (Goldstein et al. 2012). FDX is a time-dependent inhibitor of $C$. difficile growth (Babakhani et al. 2011), is more potent in vitro against C. difficile than vancomycin or metronidazole (Goldstein et al. 2012), and in vitro FDX inhibits $C$. difficile toxin A/B production (Allen et al. 2013) and the outgrowth of $C$. difficile spores
(Allen et al. 2013). FDX is effective against all ribotypes of $C$. difficile tested in vitro (Goldstein et al. 2012), although the FDX $\mathrm{MIC}_{90}$ is higher against B1/NAP1 strains of $C$. difficile than against other ribotypes (Goldstein et al. 2011), and clinical trials showed that FDX was less likely to prevent relapse from NAP1 strains of C. difficile (Louie et al. 2011; Cornely et al. 2012). 


\section{FREQUENCIES AND MECHANISMS OF REDUCED SUSCEPTIBILITY TO FDX}

Point mutations conferring loss of susceptibility of Bacillus subtilis, Mycobacterium tuberculosis, Enterococcus faecalis, and C. difficile to FDX were typically selected in the genes encoding the $\beta$ - and $\beta^{\prime}$-subunits of RNAP (encoded by $r p o B$ and $r p o C$, respectively) (Gualtieri et al. 2006; Kurabachew et al. 2008; Gualtieri et al. 2009; Seddon et al. 2011; Srivastava et al. 2011; Seddon and Sears 2012; Babakhani et al. 2014; Leeds et al. 2014). Shortly after the mechanism of action of FDX was first reported, Sonenshein et al. (1977) published the first report of B. subtilis mutants selected on superinhibitory concentrations of the compound that helped to validate RNAP as the target of the antibacterial activity. In early studies with $C$. difficile, Swanson et al. (1991) reported attempts to select mutants of a strain of $C$. difficile with reduced susceptibility to FDX; however, they were unable to do so using the reported experimental design (the frequency of resistance was reported to be $<2.8 \times 10^{-8}$ ).

Seddon et al. (2011) first reported the in vitro selection of spontaneous single-step $C$. difficile mutants on superinhibitory concentrations FDX in a conference poster (Table 1). Based on the methods reported, mutant frequencies of $>1 \times 10^{-8}$ were observed. The study included two reference strains (ATCC 9689 and ATCC 700057), which were selected on four or eight times the MIC of FDX. Selected mutants had single amino acid changes in the $\beta$-subunit (Gly1074Lys, Val1143Phe, or Val1143Asp) or the $\beta^{\prime}$-subunit (Asp237Tyr) of RNAP, which shifted the FDX MIC by 16- to $>64$-fold above that observed for the parental strains. In a conference poster the following year, Seddon and Sears (2012) reported additional in vitro selection data for $C$. difficile (Table 1). The study included one reference strain (ATCC 9689) and one clinical isolate (ORG916) of $C$. difficile. Mutants were selected on 8-64 times the MIC of FDX at a frequency of

Table 1. Frequencies and mechanisms of spontaneous $C$. difficile mutants selected in a single step on FDX

\begin{tabular}{|c|c|c|c|c|c|}
\hline Study & Strain & $\begin{array}{l}\text { Mutant } \\
\text { frequency }\end{array}$ & $\begin{array}{c}\text { Selecting } \\
\text { concentration }\end{array}$ & Amino acid change & $\begin{array}{l}\text { Fold change } \\
\text { in FDX MIC }\end{array}$ \\
\hline $\begin{array}{l}\text { Swanson et al. } \\
1991\end{array}$ & ATCC 9689 & $<2.8 \times 10^{-8}$ & $4-8 \times \mathrm{MIC}$ & None & None \\
\hline \multirow[t]{2}{*}{$\begin{array}{l}\text { Seddon et al. } \\
2011\end{array}$} & ATCC9689 & $>1 \times 10^{-8}$ & $4-8 \times \mathrm{MIC}$ & $\begin{array}{r}\beta \text {-subunit G1074K; } \\
\text { V1143F; V1143D }\end{array}$ & 32 to $>64 \times \mathrm{MIC}$ \\
\hline & ATCC 700057 & $>1 \times 10^{-8}$ & $4-8 \times \mathrm{MIC}$ & $\beta^{\prime}$-subunit D237Y & $16 \times \mathrm{MIC}$ \\
\hline \multirow[t]{2}{*}{$\begin{array}{l}\text { Seddon and } \\
\text { Sears } 2012\end{array}$} & ATCC 9689 & $\leq 4 \times 10^{-10 a}$ & $16-64 \times \mathrm{MIC}$ & $\begin{array}{l}\beta \text {-subunit V1143G; } \\
\text { V1143D; } \\
\beta^{\prime} \text {-subunit R89G }\end{array}$ & $64-8192 \times \mathrm{MIC}$ \\
\hline & ORG 916 & $\leq 5 \times 10^{-10 a}$ & $8-32 \times \mathrm{MIC}$ & $\begin{array}{l}\beta \text {-subunit Q1074K; } \\
\text { Q1074H; V1143-G; } \\
\beta^{\prime} \text {-subunit I10R; } \\
\text { R89G }\end{array}$ & $16-64 \times \mathrm{MIC}$ \\
\hline \multirow[t]{4}{*}{$\begin{array}{l}\text { Babakhani et al. } \\
2014\end{array}$} & ATCC 9689 & $\leq 1.28 \times 10^{-8}$ & $4-8 \times \mathrm{MIC}$ & $\begin{array}{l}\beta \text {-subunit Q1074K; } \\
\text { V1143F; } \beta^{\prime} \text {-subunit } \\
\text { D237Y }\end{array}$ & $16 \times \mathrm{MIC}$ \\
\hline & ATCC 700057 & $<1.41 \times 10^{-9}$ & $4-8 \times \mathrm{MIC}$ & None & \\
\hline & ORG911 & $<3.58 \times 10^{-9}$ & $4-8 \times \mathrm{MIC}$ & None & \\
\hline & ORG916 & $<2.71 \times 10^{-9}$ & $4-8 \times \mathrm{MIC}$ & None & \\
\hline \multirow{2}{*}{$\begin{array}{l}\text { Locher et al. } \\
\qquad 2014 a\end{array}$} & ATCC 9689 & $\leq 1.3 \times 10^{-8}$ & $2-8 \times \mathrm{MIC}$ & ND & $\geq 64 \times \mathrm{MIC}$ \\
\hline & $\begin{array}{l}\text { NCTC } 13366 \\
\text { A-1410 }\end{array}$ & $\begin{array}{r}\leq 7.2 \times 10^{-7} \\
11 \times 10^{-6}\end{array}$ & $\begin{array}{l}4-8 \times \mathrm{MIC} \\
8 \times \mathrm{MIC}\end{array}$ & ND & $16 \times$ MIC \\
\hline
\end{tabular}

${ }^{a}$ Calculated from the methods/results. 
J.A. Leeds

$\leq 4 \times 10^{-10}$, based on the methods reported. The FDX MIC against the selected mutants shifted 16-8192 times the MIC reported for the parental strains. Selected mutants had single amino acid substitutions within the RNAP $\beta$ subunit (Gln1074Lys, Gln1074His, Val1143Gly, and Val1143Asp) or $\beta^{\prime}$-subunit (Ile10Arg and Arg89Gly).

In a more recent publication, the same group (Babakhani et al. 2014) described the results of selecting for spontaneous single-step mutants of four strains of $C$. difficile on $4 \times$ and $8 \times$ MIC of FDX (Table 1 ). The study included two reference strains (ATCC 700057 and ATCC 9689) and two clinical isolates (ORG911 and ORG916). Rifaximin and VAN were included as comparators for the selections. Although rifaximin selected for spontaneous single-step mutants of $C$. difficile at a frequency of $\leq 1.73 \times$ $10^{-7}$ on $8 \times$ MIC of drug, no mutants were selected on $8 \times$ MIC of FDX or vancomycin (VAN) and the resistance frequency was reported to be $<1.4 \times 10^{-9}$. When assays were conducted with $4 \times$ MIC of FDX, mutants of ATCC 9689 were selected at a frequency of $1.28 \times$ $10^{-8}$ and the MIC of FDX against these mutants shifted 16-fold. The mutants harbored amino acid substitutions in RNAP subunit $\beta$ (Gln1074Lys or Val1143Phe) or in subunit $\beta^{\prime}$ of Asp237Tyr. The same or greater magnitude of MIC shift (16- to $\geq 64$-fold) was observed for two mutants of $C$. difficile strains ATCC 700057 and ATCC 43255 that were selected via serial passage (Babakhani et al. 2014). The investigators also describe a mutant strain of ATCC 43255 with a $\geq 64$-fold shift in FDX MIC over the parental strain, but no mutant frequencies or amino acid substitutions were reported for this strain. None of the mutants selected on FDX showed reduced susceptibility to the clinically used RNAP inhibitor rifampin (RIF), supporting the model that the binding site of FDX does not overlap with that of RIF or other RNAP inhibitors that function through sites other than the switch region of RNAP (Srivastava et al. 2011). The investigators (Babakhani et al. 2014) described in vitro synergy studies with FDX and RIF, emphasizing the nonoverlapping mechanisms of resistance, which raises the potential to combine the two agents to suppress resistance development to either agent alone; the outcomes of such combination studies have not been reported.

Locher et al. selected for single-step spontaneous mutants of $C$. difficile on 2-8 $\times$ MIC of FDX, as well as by serial passage (Table 1) (Locher et al. 2014a). Mutants were selected on $8 \times$ MIC of FDX at much higher frequencies $\left(\leq 1.1 \times 10^{-6}\right)$ than those reported by Babakhani et al. (2014). Spontaneous mutants were selected on all four strains of $C$. difficile that were tested including ATCC 9689 and three clinical isolates. Mutants selected in a single step were then subjected to two additional sequential rounds of selection on higher concentrations of FDX. The MICs of FDX against mutants selected in a single step or in multiple steps ranged from $2 \mu \mathrm{g} / \mathrm{mL}$ to $>128 \mu \mathrm{g} / \mathrm{mL}$ and accounted for MIC shifts of eight- to $>4000$-fold over the parental strains. The mechanisms of resistance to FDX were not reported in this publication.

Leeds et al. subjected C. difficile strain ATCC 43255 and three clinical isolates of $C$. difficile to 10 passages on a range of concentrations of FDX (Leeds et al. 2014). The genomes of selected C. difficile mutants with reduced susceptibility to the selecting agents and their isogenic parental strains were fully sequenced to determine the single-nucleotide polymorphisms (SNPs) that were observed in the mutant background compared with the susceptible parent. When passaged on FDX, a 16-fold decrease in susceptibility was observed for clinical strain NB95013, and a 64-fold decrease in susceptibility was observed for clinical strain NB95026. There was a twofold change in FDX susceptibility for clinical strain NB95031 and a fourfold shift in FDX susceptibility for clinical strain NB95047. The NB95026 mutant showing a 64-fold decrease in susceptibility to FDX harbored a Gln1073Arg substitution in RNAP subunit $\beta$. Previous work by Seddon et al. (2011) had identified lysine and histidine substitutions at the same residue (numbered residue 1074 in Seddon et al. 2011 and Seddon and Sears 2012). The NB95013 mutant showing a 15-fold decreased 
susceptibility to FDX harbored a deletion in CD22120 (marR homolog), resulting in a frameshift after amino acid 117 of a homolog of the MarR family of transcriptional regulators. This finding represented the first report of a mechanism outside RNAP that may alter susceptibility to FDX. Although MarR is associated with multidrug resistance, the investigators did not observe reduced susceptibility to antibiotics other than FDX in that study.

Although notable, the high variability observed for frequencies of selecting mutants of C. difficile with reduced susceptibility to FDX (Table 1) may be owing to variations in methodology combined with too few replicates in any one study; therefore, it is not clear if the differences are biologically meaningful.

\section{C. difficile WITH REDUCED SUSCEPTIBILITY TO FDX ISOLATED FROM PATIENTS TREATED WITH FDX IN PHASE III CLINICAL TRIALS (STUDIES OPT-80-003 AND -004)}

Goldstein et al. reported that the FDX MIC for all baseline isolates from the modified intentto-treat (mITT) and per protocol populations across both phase III studies was $0.25 \mu \mathrm{g} / \mathrm{mL}$ (Goldstein et al. 2011). Although there were no instances of FDX MIC $>0.5 \mu \mathrm{g} / \mathrm{mL}$ among the baseline $C$. difficile isolates from the 26 patients in the per protocol population who were clinical failures following treatment with FDX, a single strain of $C$. difficile with reduced susceptibility to FDX was isolated from a FDX-treated, clinically cured patient who suffered a recurrence. The strain, which harbored a Val1143Gly substitution in the RNAP $\beta$-subunit was isolated at the time of recurrence and the FDX MIC was $16 \mu \mathrm{g} / \mathrm{mL}$ (Goldstein et al. 2011).

Eyre et al. reported whole genome sequences of the 28 pairs of isolates available at baseline and recurrence in FDX-treated patients from the ITT population in the pooled phase III studies $(\sim 41 \%$ of the total intent-to-treat (ITT) population receiving FDX who suffered recurrences of CDI during the study) (Eyre et al. 2014). In this analysis, isolates from two ITT patients who suffered recurrences were reported to have mutations in the target gene $r p o B$. One of those isolates is the same one reported previously by Goldstein et al. (2011) against which FDX had a MIC of $16 \mu \mathrm{g} / \mathrm{mL}$. In addition, a second strain was isolated from a patient with recurrence that showed a 10 -fold reduction in susceptibility to FDX (FDX MIC $=0.015 \mu \mathrm{g} /$ $\mathrm{mL}$ at baseline and $0.125 \mu \mathrm{g} / \mathrm{mL}$ at follow-up). The strain harbored a Val1143Leu substitution in RNAP $\beta$-subunit. Eyre et al. (2014) indicated that because neither mutation was observed in isolates from any other patient, it suggests that the mutants are uncommon. However, sequencing data from only 28 baseline and matched-patient postbaseline isolates from the FDX arm of the combined phase III trials, which included a total of 572 subjects who received FDX, have been reported, so more surveillance and posttreatment isolates would need to be tested to understand the true prevalence of such mutants. Eyre et al. (2014) also reported other nonsynonymous SNPs, including one in a hypothetical protein and one in a putative PTS system, which were identified in strains from patients treated with FDX who experienced a recurrence of disease following clinical cure at end of treatment. The extent to which any of these substitutions, whether in the target of FDX or elsewhere, contribute to recurrence of disease is unknown. Regular postmarketing surveillance data will be required to inform whether the use of FDX to treat $C$. difficile infection results in the selection for additional mutants with reduced susceptibility in patients or in the environment.

\section{ANTIMICROBIAL MECHANISM OF ACTION OF LFF571}

LFF571 is a semisynthetic derivative of the natural product GE2770A (Fig. 1) (LaMarche et al. 2012). Scientists at Le Petit Research Center identified GE2270A, a thiopeptide-based secondary metabolite isolated from the fermentation broth of Planobispora rosea, in a screen for Staphylococcus aureus growth inhibitors that were antagonized by the addition of exogenous elongation factor Tu (EF-Tu) into the assay system (Selva et al. 1991, 1997; Landini et al. 1996); 
J.A. Leeds

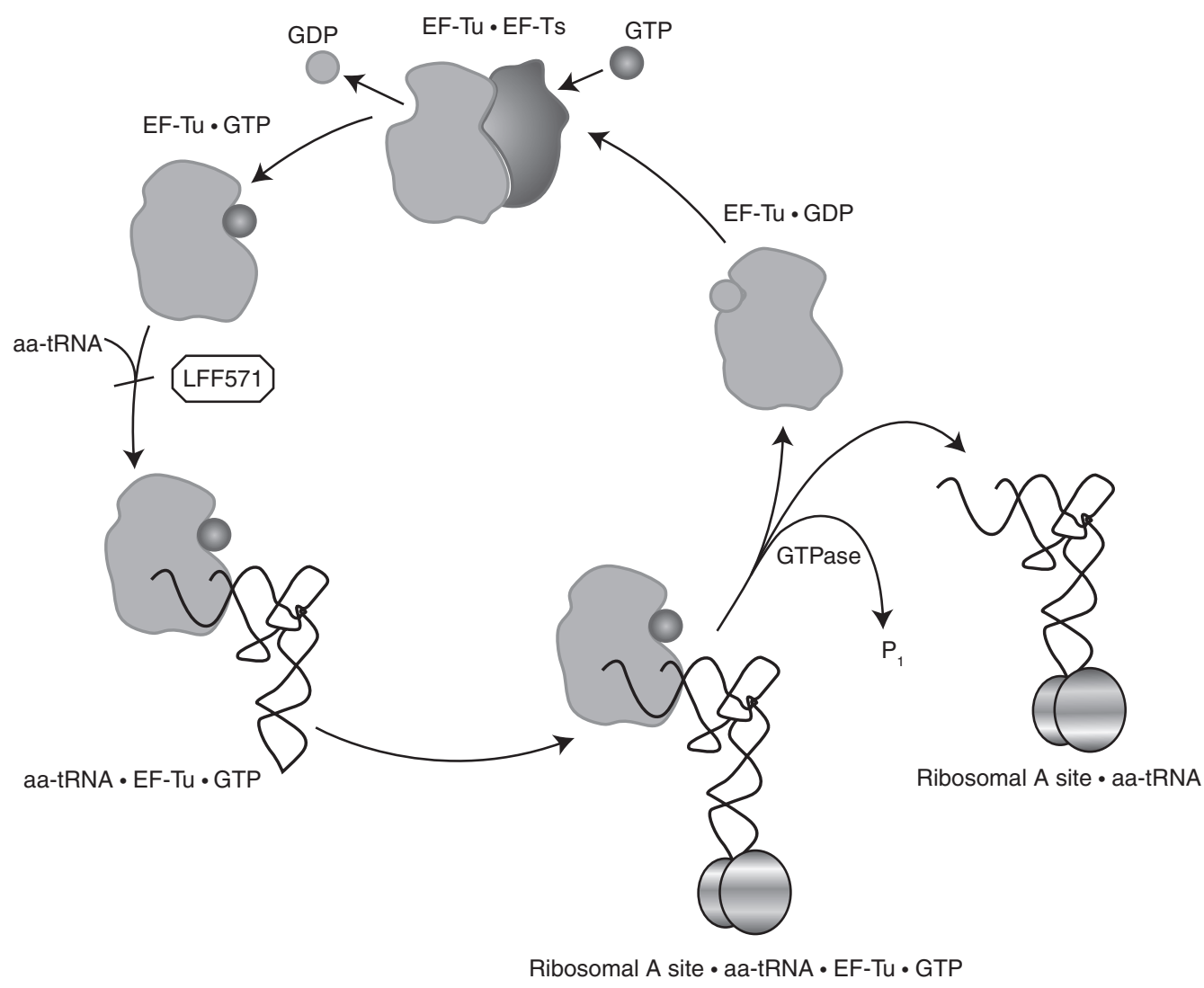

Figure 2. EF-Tu functional cycle with point of LFF571 inhibition indicated. GDP, Guanosine diphosphate; GTP, guanosine triphosphate.

the structure assignment for GE2270A was corrected in subsequent publications (Tavecchia et al. 1994, 1995). As a human therapeutic candidate, LFF571 has a novel mechanism of action, in that, like the natural product precursor GE2270A, it binds to and inhibits the function of bacterial EF-Tu (Landini et al. 1996; Leeds et al. 2012).

EF-Tu is one of three proteins (along with EF-Ts and EF-G) that are required, after formation of the 70S initiation complex of the ribosome, to catalyze the subsequent steps in peptide chain elongation (Fig. 2) (reviewed in Voorhees and Ramakrishnan 2013). EF-Tu is the chaperone that delivers aminoacylated tRNAs to the A site of the ribosome in the form of the ternary complex EF-Tu - guanosine triphosphate (GTP) • aa-tRNA (Fahnestock et al. 1972; Stark et al. 1997). Subsequent GTP hydrolysis causes the release of EF-Tu in complex with guanosine diphosphate (GDP). EF-Tu is then reactivated by the action of EF-Ts, which catalyzes the GDP/ GTP nucleotide exchange and renders EF-Tu competent for carrying out the next round of tRNA delivery (Miller and Weissbach 1970).

Because the binding site overlaps with that of tRNA, LFF571 inhibits protein synthesis by interfering with the ability for EF-Tu to deliver aminoacylated tRNA to the ribosome (Deng et al. 2011; Leeds et al. 2012). There are several other natural products that are known to inhibit the function of EF-Tu by the same or other mechanisms including kirromycin, pulvomycin, thiomuracin, amithiamycin, and efrotomycin (Parmeggiani and Nissen 2006; Morris et al. 2009). Synthetic small molecule inhibitors of EF-Tu have also been disclosed in publications (Deibel et al. 2004; Jayasekera et al. 2005). 
To date, no EF-Tu inhibitors have been registered for clinical use in humans, although a different analog of GE2270A with an unreported structure (BI-K-0376 or "VIC-acne") was investigated as a topical agent for the treatment of acne (reviewed in Butler 2005).

LFF571, like FDX, is active in vitro against its molecular target (EF-Tu) from Gram-positive and Gram-negative organisms (Deng et al. 2011); however, the antibacterial spectrum of LFF571 is limited to Gram-positive aerobes and anaerobes (Citron et al. 2012). The $K_{d}$ of LFF571 binding to $C$. difficile EF-Tu $\bullet$ GDP is $\sim 130 \mathrm{~nm}$ (Deng et al. 2011). LFF571 is effective against all ribotypes of $C$. difficile tested $\left(\mathrm{MIC}_{90}\right.$ $=0.25 \mu \mathrm{g} / \mathrm{mL}$ ) and is more potent in vitro against $C$. difficile than vancomycin and metronidazole (Citron et al. 2012; Debast et al. 2013). LFF571 was shown to be efficacious and safe in a proof-of-concept study in humans with mild to moderate CDI (Mullane et al. 2015), and to have low oral bioavailability and high fecal concentrations in infected patients (Bhansali et al. 2015). Anticipated by the novel mechanism of antibacterial activity, LFF571 is potent against bacteria with reduced susceptibility or resistance to marketed antibiotics (Citron et al. 2012). Supporting its use as a therapeutic for CDI, LFF571 reduces $C$. difficile toxin A/B levels in culture supernatants even at sub-MIC concentrations (Sachdeva and Leeds 2015).

\section{FREQUENCIES AND MECHANISMS OF REDUCED SUSCEPTIBILITY TO LFF571}

LFF571 is a semisynthetic derivative of the natural EF-Tu inhibitor GE2270A. The GE2270Aproducing strain of $P$. rosea has a naturally occurring, functional EF-Tu variant (EF-Tu1) that is not susceptible to inhibition by GE2270A (Mohrle et al. 1997). Zuurmond et al. (2000) systematically introduced individual amino acid substitutions that are found in the native P. rosea EF-Tu1 into the GE2270A-sensitive EFTu protein from E. coli. They found that only two individual substitutions could account for the naturally occurring resistance to GE2270A, namely, Gly257Ser or Gly275Ala (E. coli num- bering), both of which are found in GE2270Abinding region of EF-Tu domain II. The locations of the substitutions in the protein are supported by the cocrystal data showing that GE2270A binds to domain II of bacterial EF$\mathrm{Tu}$, making contact with residues 215-230, 256-264, and 273-277 (Heffron and Jurnak 2000).

$\mathrm{EF}-\mathrm{Tu}$ is one of the most abundant proteins in the cell, representing up to $10 \%$ of the total protein content (Ishihama et al. 2008). There is approximately one EF-Tu molecule for every tRNA and this ratio is constant under different growth conditions (Furano 1975). In many organisms, including C. difficile, there are two copies of the genes encoding EF-Tu (tufA and tufB) (Jaskunas et al. 1975; Sela et al. 1989; Ke et al. 2000; Leeds et al. 2012). One altered copy of EF$\mathrm{Tu}$ is sufficient for reduced susceptibility to GE2270A or LFF571 (Zuurmond et al. 2000; Leeds et al. 2012), unlike the mechanism of resistance to kirromycin, an inhibitor of the GTPase activity of EF-Tu, against which reduced susceptibility is only achieved when both copies of tuf are mutated (reviewed in Parmeggiani and Nissen 2006). Nevertheless, despite the high copy number of the target protein and the dominance of resistance, single-step spontaneous mutants of $C$. difficile with reduced susceptibility to LFF571 are selected in vitro at low frequencies $\left(\leq 1.2 \times 10^{-9}\right)$ (Table 2) (Leeds et al. 2012). Mutant selections were attempted with four strains of $C$. difficile (three clinical strains and one high-toxin expressing-type strain ATCC 43255); reduced susceptibility to LFF571 was observed at the following frequencies: $1.7 \times$ $10^{-10}$ (NB95002 selected at 0.5 and $1 \mu \mathrm{g} /$ $\mathrm{mL}$ LFF571), $1.2 \times 10^{-9}$ and $<6.2 \times 10^{-10}$ (NB95013 at 0.5 and $1 \mu \mathrm{g} / \mathrm{mL}$, respectively), and $3.0 \times 10^{-11}$ and $<3.0 \times 10^{-11}$ (NB95026 at 0.5 and $1 \mu \mathrm{g} / \mathrm{mL}$, respectively). No mutants of NB95031 were selected on LFF571 under the conditions tested $\left(<4.5 \times 10^{-11}\right)$.

All $C$. difficile mutants selected in vitro on LFF571 showed tufB mutation G782A, resulting in amino acid substitution G260E; NB95013JAL0759 harbored the G782A change in both tuf $A$ and tufB, which are identical in sequence in this pathogen (Leeds et al. 2012). Residue 
J.A. Leeds

Table 2. Frequencies and genotypes of spontaneous $C$. difficile mutants selected in a single step on LFF571

\begin{tabular}{lccllc}
\hline Strain & $\begin{array}{c}\text { Selecting } \\
\text { concentration }\end{array}$ & $\begin{array}{c}\text { Mutant } \\
\text { frequency }\end{array}$ & $\begin{array}{c}\text { Mutant selected on } \\
\text { LFF571 }\end{array}$ & $\begin{array}{c}\text { Amino acid } \\
\text { change }\end{array}$ & $\begin{array}{c}\text { Fold change in LFF571 } \\
\text { MIC }\end{array}$ \\
\hline NB95002 & $4 \times$ MIC & $1.7 \times 10^{-10}$ & NB95002-JAL0777 & tufB: G260E & $>256 \times$ MIC \\
NB95013 & $1 \times$ MIC & $1.2 \times 10^{-9}$ & NB95013-JAL0758 & tufB: G260E & $>512 \times$ MIC \\
& & & NB95013-JAL0759 & tufA: G260E tufB: & $>512 \times$ MIC \\
& & & G260E & \\
NB95026 & $1 \times$ MIC & $3.0 \times 10^{-11}$ & NB95026-JAL0792 & tufB: G260E & $>512 \times$ MIC \\
& $2 \times$ MIC & $<3.0 \times 10^{-11}$ & None & None & \\
NB95031 & $1 \times$ MIC & $<4.5 \times 10^{-11}$ & None & None & \\
& $2 \times$ MIC & $<4.5 \times 10^{-11}$ & None & None & \\
\hline
\end{tabular}

G260 in C. difficile EF-Tu is synonymous with G257 in E. coli EF-Tu, one of the two residues in which amino acid substitutions resulted in GE2270A-resistant EF-Tu. The proposed mechanism of resistance to LFF571 is that, rather than displacing the inhibitor, the G260E gainof-function substitution restores the interactions between aa-tRNA and EF-Tu • GTP • LFF571. Several lines of evidence support the model that LFF571 and tRNA bind simultaneously to the mutant EF-Tu • GTP complex. First, LFF571 retains weak antibacterial activity against the EF-Tu G260E mutants (MIC 128$256 \mu \mathrm{g} / \mathrm{mL}$ ) (Leeds et al. 2012). Second, Zuurmond et al. (2000) reported that the affinity of the natural product inhibitor GE2270A for wild-type E. coli EF-Tu • GTP is the same as for the G260S mutant, and in the presence of the GE2270A, the affinity of aa-tRNA for the G260S mutant increases $100 \times$ over its affinity for wild-type EF-Tu • GTP/GE2270A. Finally, the affinity of GE2270A for E. coli EF-Tu • GDP is dramatically decreased by G260S, so on GTP hydrolysis at the ribosome, the inhibitor more quickly dissociates, leaving the aa-tRNA in the A site. Therefore, the mechanism of resistance to this thiopeptide class, in general, may not be a result of decreased affinity of the inhibitor to EF-Tu - GTP; rather, the mutant restores the ability of the GTP-bound enzyme to bind the substrate aa-tRNA and the mutant confers a more rapid dissociation of the inhibitor from the mutant EF-Tu/ribosomal complex once the aa-tRNA has engaged the A site (Zuurmond et al. 2000). This proposed mechanism of resis- tance to LFF571 is a model based on the behavior of the natural analog GE2270A and would require structural and affinity studies with LFF571 to be validated.

\section{CONCLUDING REMARKS}

FDX and LFF571 are novel antibacterial agents with clinically unprecedented mechanisms of target inhibition that exemplify compounds with a clinical focus directed at a single organism-C. difficile. Both compounds select for reduced susceptibility in $C$. difficile in vitro, and mutants with reduced susceptibility to FDX have been reported to be isolated at the time of recurrence from two patients who received FDX as a treatment for CDI. Because C. difficile is a spore-forming species, selection for mutants in patients could lead to dissemination of mutant spores, which, over time, could shift the susceptibility of the compounds for $C$. difficile strains in the general population. Routine susceptibility testing is not used to guide the choice of appropriate therapy for CDI. Therefore, it would fall to regular surveillance studies or epidemiological data from outbreaks to inform trends in the loss of susceptibility to such agents. Whether such a shift in susceptibility would have an impact on the ability to treat $C$. difficile with such agents is unknown, especially given that the concentrations of these agents in the colon, at the site of antibacterial action, is typically well above the MIC for the mutants (Louie et al. 2011; Bhansali et al. 2015). 
Although not approved for use, other drugs, such as rifaximin and fusidic acid, against which high-frequency single-step resistance can be selected in C. difficile, are occasionally used to treat CDI. Attempts to understand the impact of mutants with reduced susceptibility to these agents on therapeutic outcome have been reported (Noren et al. 2006; Mattila et al. 2013). For example, a study comparing fusidic acid with metronidazole for the treatment of CDI showed that although all isolates from patients randomized to fusidic acid were susceptible at baseline, 55\% $(11 / 20)$ of posttreatment isolates were resistant to fusidic acid (median MIC $>256 \mu \mathrm{g} / \mathrm{mL}$ ) (Noren et al. 2006). Clinical failure and relapse, among those treated with fusidic acid, occurred in $12 \%$ and $34 \%$ of the patients with fusidic acid-resistant strains posttreatment versus $6 \%$ and $17 \%$ of the patients with fusidic acid-sensitive strains posttreatment. Persistence of $C$. difficile in stool culture at follow-up predicted failure/relapse regardless of treatment assignment. One or two nonsynonymous substitutions in EF-G (the target of fusidic acid) were responsible for the shift in susceptibility in C. difficile (Noren et al. 2007). Fusidic acid fecal concentrations have not been directly reported; however, $\sim 2 \%$ of an oral dose is excreted unchanged (Reeves 1987).

Recently, Adams et al. reported that the serial passage of $C$. difficile in subinhibitory concentrations of the phase III CDI compound surotomycin resulted in mutants with an eight- to16fold shift in susceptibility to both surotomycin and daptomycin, the clinically used natural product antibiotic from which surotomycin is derived (Adams et al. 2015). In addition, surotomycin also selected for mutants of Enterococcus faecium and E. faecalis that are cross-resistant to daptomycin (Mascio et al. 2014). Therefore, even with antibiotics for which the mechanism of inhibition involves a complex membrane target, rather than a single-gene product, one can select for loss of susceptibility that is stable and imparts cross-resistance of other pathogens to the drugs used clinically to treat infections with those organisms.

Perhaps with the increasing focus on new agents for CDI, especially in the era of target- based drug discovery, the paradigm for guiding appropriate treatment will shift, and will encompass some form of susceptibility testing to insure adequate therapy. Or perhaps the high drug exposures will obviate the need. The data coming from the many trials in CDI, as well as the surveillance studies for newly registered drugs, will help to inform this decision.

\section{ACKNOWLEDGMENTS}

I am grateful to Johanne Blais for helpful suggestions and assistance with the presentation of data.

\section{REFERENCES}

Adams HM, Li X, Mascio C, Chesnel L, Palmer KL. 2015 Mutations associated with reduced surotomycin susceptibility in Clostridium difficile and Enterococcus species. Antimicrob Agents Chemother 59: 4139-4147.

Allen CA, Babakhani F, Sears P, Nguyen L, Sorg JA. 2013. Both fidaxomicin and vancomycin inhibit outgrowth of Clostridium difficile spores. Antimicrob Agents Chemother 57: 664-667.

Artsimovitch I, Seddon J, Sears P. 2012. Fidaxomicin is an inhibitor of the initiation of bacterial RNA synthesis. Clin Infect Diseases 55: S127-S131.

Babakhani F, Gomez A, Robert N, Sears P. 2011. Killing kinetics of fidaxomicin and its major metabolite, OP1118, against Clostridium difficile. J Med Microbiol 60: 1213-1217.

Babakhani F, Seddon J, Sears P. 2014. Comparative microbiological studies of transcription inhibitors fidaxomicin and the rifamycins in Clostridium difficile. Antimicrob Agents Chemother 58: 2934-2937.

Bagdasarian N, Rao K, Malani PN. 2015. Diagnosis and treatment of Clostridium difficile in adults: A systematic review. JAMA 313: 398-408.

Bauer MP, Kuijper EJ, van Dissel JT. 2009. European Society of Clinical Microbiology and Infectious Diseases (ESCMID): Treatment guidance document for Clostridium difficile infection (CDI). Clin Microbiol Infect 15: 10671079.

Bedeschi A, Fonte P, Fronza G, Fuganti C, Serra S. 2014. The co-identity of lipiarmycin A3 and tiacumicin B. Nat Prod Commun 9: 237-240.

Bhansali SG, Mullane K, Ting LS, Leeds JA, Dabovic K, Praestgaard J, Pertel P. 2015. Pharmacokinetics of LFF571 and vancomycin in patients with moderate Clostridium difficile infections. Antimicrob Agents Chemother 59: $1441-1445$.

Butler MS. 2005. Natural products to drugs: Natural product derived compounds in clinical trials. Nat Prod Rep 22: $162-195$.

Citron DM, Tyrrell KL, Merriam CV, Goldstein EJ. 2012. Comparative in vitro activities of LFF571 against Clos- 
J.A. Leeds

tridium difficile and 630 other intestinal strains of aerobic and anaerobic bacteria. Antimicrob Agents Chemother 56: 2493-2503.

Cohen SH, Gerding DN, Johnson S, Kelly CP, Loo VG, McDonald LC, Pepin J, Wilcox MH. 2010. Clinical practice guidelines for Clostridium difficile infection in adults: 2010 update by the society for healthcare epidemiology of America (SHEA) and the infectious diseases society of America (IDSA). Infect Control Hosp Epidemiol 31: 431455.

Cornely OA, Crook DW, Esposito R, Poirier A, Somero MS Weiss K, Sears P, Gorbach S. 2012. Fidaxomicin versus vancomycin for infection with Clostridium difficile in Europe, Canada, and the USA: A double-blind, non-inferiority, randomised controlled trial. Lancet Infect Dis 12: 281-289.

Coronelli C, White RJ, Lancini GC, Parenti F. 1975. Lipiarmycin, a new antibiotic from Actinoplanes. II: Isolation, chemical, biological and biochemical characterization. $J$ Antibiot (Tokyo) 28: 253-259.

Debast SB, Bauer MP, Sanders IM, Wilcox MH, Kuijper EJ. 2013. Antimicrobial activity of LFF571 and three treatment agents against Clostridium difficile isolates collected for a pan-European survey in 2008: Clinical and therapeutic implications. J Antimicrob Chemother 68: 13051311.

Debast SB, Bauer MP, Kuijper EJ. 2014. European Society of Clinical Microbiology and Infectious Diseases: Update of the treatment guidance document for Clostridium diffcile infection. Clin Microbiol Infect 20: 1-26.

Deibel MR Jr, Bodnar AL, Yem AW, Wolfe CL, Heckaman CL, Bohanon MJ, Mathews WR, Sweeney MT, Zurenko GE, Marotti KR, et al. 2004. Immobilization of a novel antibacterial agent on solid phase and subsequent isolation of EF-Tu. Bioconjug Chem 15: 333-343.

Deng GLL, Palestrant DJ, Whitehead L, Sachdeva M, DzinkFox J, LaMarche MJ, Leeds JA. 2011. Investigation of mode of binding of elongation factor Tu inhibitor LFF571. In 51st Interscience Conference on Antimicrobial Agents and Chemotherapy. Chicago, IL.

Evans CT, Safdar N. 2015. Current trends in the epidemiology and outcomes of Clostridium difficile infection. Clin Infect Dis 60: S66-S71.

Eyre DW, Babakhani F, Griffiths D, Seddon J, Del Ojo Elias C, Gorbach SL, Peto TE, Crook DW, Walker AS. 2014 Whole-genome sequencing demonstrates that fidaxomicin is superior to vancomycin for preventing reinfection and relapse of infection with Clostridium difficile. J Infect Dis 209: 1446-1451.

Fahnestock S, Weissbach H, Rich A. 1972. Formation of a ternary complex of phenyllactyl-tRNA with transfer factor Tu and GTP. Biochim Biophys Acta 269: 62-66.

Freeman J, Vernon J, Morris K, Nicholson S, Todhunter S, Longshaw C, Wilcox MH. 2015. Pan-European longitudinal surveillance of antibiotic resistance among prevalent Clostridium difficile ribotypes. Clin Microbiol Infect 21: 248.e9-248.e16.

Furano AV. 1975. Content of elongation factor Tu in Escherichia coli. Proc Natl Acad Sci 72: 4780-4784.

Goldstein EJ, Citron DM, Sears P, Babakhani F, Sambol SP, Gerding DN. 2011. Comparative susceptibilities to fidaxomicin (OPT-80) of isolates collected at baseline, recur- rence, and failure from patients in two phase III trials of fidaxomicin against Clostridium difficile infection. Antimicrob Agents Chemother 55: 5194-5199.

Goldstein EJ, Babakhani F, Citron DM. 2012. Antimicrobial activities of fidaxomicin. Clin Infect Dis 55: S143-S148.

Gualtieri M, Villain-Guillot P, Latouche J, Leonetti JP, Bastide L. 2006. Mutation in the Bacillus subtilis RNA polymerase $\beta^{\prime}$-subunit confers resistance to lipiarmycin. Antimicrob Agents Chemother 50: 401-402.

Gualtieri M, Tupin A, Brodolin K, Leonetti JP. 2009. Frequency and characterisation of spontaneous lipiarmycinresistant Enterococcus faecalis mutants selected in vitro. Int J Antimicrob Agents 34: 605-606.

Healy VL, Lessard IA, Roper DI, Knox JR, Walsh CT. 2000 Vancomycin resistance in enterococci: Reprogramming of the D-ala-D-Ala ligases in bacterial peptidoglycan biosynthesis. Chem Biol 7: R109-R119.

Hecht DOD, Gerding D. 2012. Activity of LFF571 against 103 clinical isolates of C. difficile. In 22nd European Congress on Clinical Microbiology and Infectious Diseases. London, UK.

Heffron SE, Jurnak F. 2000. Structure of an EF-Tu complex with a thiazolyl peptide antibiotic determined at $2.35 \mathrm{~A}$ resolution: Atomic basis for GE2270A inhibition of EFTu. Biochemistry 39: 37-45.

Hensgens MP, Dekkers OM, Demeulemeester A, Buiting AG, Bloembergen P, van Benthem BH, Le Cessie S, Kuijper EJ. 2014. Diarrhoea in general practice: When should a Clostridium difficile infection be considered? Results of a nested case-control study. Clin Microbiol Infect 20: O1067-O1074.

Ishihama Y, Schmidt T, Rappsilber J, Mann M, Hartl FU, Kerner MJ, Frishman D. 2008. Protein abundance profiling of the Escherichia coli cytosol. BMC Genomics 9: 102.

Ivarsson ME, Leroux JC, Castagner B. 2015. Investigational new treatments for Clostridium difficile infection. Drug Discov Today 20: 602-608.

Jaskunas SR, Lindahl L, Nomura M. 1975. Identification of two copies of the gene for the elongation factor EF-Tu in E. coli. Nature 257: 458-462.

Jayasekera MM, Onheiber K, Keith J, Venkatesan H, Santillan A, Stocking EM, Tang L, Miller J, Gomez L, Rhead B, et al. 2005. Identification of novel inhibitors of bacterial translation elongation factors. Antimicrob Agents Chemother 49: 131-136.

Ke D, Boissinot M, Huletsky A, Picard FJ, Frenette J, Ouellette M, Roy PH, Bergeron MG. 2000. Evidence for horizontal gene transfer in evolution of elongation factor $\mathrm{Tu}$ in enterococci. J Bacteriol 182: 6913-6920.

Kurabachew M, Lu SH, Krastel P, Schmitt EK, Suresh BL, Goh A, Knox JE, Ma NL, Jiricek J, Beer D, et al. 2008. Lipiarmycin targets RNA polymerase and has good activity against multidrug-resistant strains of Mycobacterium tuberculosis. J Antimicrob Chemother 62: 713-719.

LaMarche MJ, Leeds JA, Amaral A, Brewer JT, Bushell SM, Deng G, Dewhurst JM, Ding J, Dzink-Fox J, Gamber G, et al. 2012. Discovery of LFF571: An investigational agent for Clostridium difficile infection. J Med Chem 55: 23762387.

Landini P, Soffientini A, Monti F, Lociuro S, Marzorati E, Islam K. 1996. Antibiotics MDL 62,879 and kirromycin 
bind to distinct and independent sites of elongation factor Tu (EF-Tu). Biochemistry 35: 15288-15294.

Leeds JA, Sachdeva M, Mullin S, Dzink-Fox J, Lamarche MJ. 2012. Mechanism of action of and mechanism of reduced susceptibility to the novel anti-Clostridium difficile compound LFF571. Antimicrob Agents Chemother 56: 4463 4465.

Leeds JA, Sachdeva M, Mullin S, Barnes SW, Ruzin A. 2014 In vitro selection, via serial passage, of Clostridium difficile mutants with reduced susceptibility to fidaxomicin or vancomycin. J Antimicrob Chemother 69: 41-44.

Lessa FC, Mu Y, Bamberg WM, Beldavs ZG, Dumyati GK, Dunn JR, Farley MM, Holzbauer SM, Meek JI, Phipps EC, et al. 2015. Burden of Clostridium difficile infection in the United States. N Engl J Med 372: 825-834.

Locher HH, Caspers P, Bruyere T, Schroeder S, Pfaff P, Knezevic A, Keck W, Ritz D. 2014a. Investigations of the mode of action and resistance development of cadazolid, a new antibiotic for treatment of Clostridium difficile infections. Antimicrob Agents Chemother 58: 901-908.

Locher HH, Seiler P, Chen X, Schroeder S, Pfaff P, Enderlin M, Klenk A, Fournier E, Hubschwerlen C, Ritz D, et al. 2014b. In vitro and in vivo antibacterial evaluation of cadazolid, a new antibiotic for treatment of Clostridium difficile infections. Antimicrob Agents Chemother 58: 892 900.

Louie TJ, Miller MA, Mullane KM, Weiss K, Lentnek A, Golan Y, Gorbach S, Sears P, Shue YK. 2011. Fidaxomicin versus vancomycin for Clostridium difficile infection. $N$ Engl J Med 364: 422-431.

Magill SS, Edwards JR, Bamberg W, Beldavs ZG, Dumyati G, Kainer MA, Lynfield R, Maloney M, McAllister-Hollod L, Nadle J, et al. 2014. Multistate point-prevalence survey of health care-associated infections. N Engl J Med 370: $1198-1208$.

Mascio CT, Chesnel L, Thorne G, Silverman JA. 2014. Surotomycin demonstrates low in vitro frequency of resistance and rapid bactericidal activity in Clostridium diffcile, Enterococcus faecalis, and Enterococcus faecium. Antimicrob Agents Chemother 58: 3976-3982.

Mattila E, Arkkila P, Mattila PS, Tarkka E, Tissari P, Anttila VJ. 2013. Rifaximin in the treatment of recurrent Clostridium difficile infection. Aliment Pharmacol Ther 37: $122-128$.

McDonald LC, Killgore GE, Thompson A, Owens RC Jr, Kazakova SV, Sambol SP, Johnson S, Gerding DN. 2005. An epidemic, toxin gene-variant strain of Clostridium difficile. N Engl J Med 353: 2433-2441.

Miller DL, Weissbach H. 1970. Interactions between the elongation factors: The displacement of GPD from the TU-GDP complex by factor Ts. Biochem Biophys Res Commun 38: 1016-1022.

Mohrle VG, Tieleman LN, Kraal B. 1997. Elongation factor Tu1 of the antibiotic GE2270A producer Planobispora rosea has an unexpected resistance profile against EF-Tu targeted antibiotics. Biochem Biophys Res Commun 230: $320-326$.

Morris RP, Leeds JA, Naegeli HU, Oberer L, Memmert K, Weber E, LaMarche MJ, Parker CN, Burrer N, Esterow S, et al. 2009. Ribosomally synthesized thiopeptide antibiotics targeting elongation factor Tu. J Am Chem Soc 131: 5946-5955.
Mullane K, Lee C, Bressler A, Buitrago M, Weiss K, Dabovic K, Praestgaard J, Leeds JA, Blais J, Pertel P. 2015. Multicenter, randomized clinical trial to compare the safety and efficacy of LFF571 and vancomycin for Clostridium difficile infections. Antimicrob Agents Chemother 59: 1435-1440.

Noren T, Wullt M, Akerlund T, Back E, Odenholt I, Burman LG. 2006. Frequent emergence of resistance in Clostridium difficile during treatment of $C$. difficile-associated diarrhea with fusidic acid. Antimicrob Agents Chemother 50: 3028-3032.

Noren T, Akerlund T, Wullt M, Burman LG, Unemo M 2007. Mutations in fusA associated with posttherapy fusidic acid resistance in Clostridium difficile. Antimicrob Agents Chemother 51: 1840-1843.

Omura S, Imamura N, Oiwa R, Kuga H, Iwata R, Masuma R, Iwai Y. 1986. Clostomicins, new antibiotics produced by Micromonospora echinospora subsp. armeniaca subsp. nov. I: Production, isolation, and physico-chemical and biological properties. J Antibiot (Tokyo) 39: 1407-1412.

Parmeggiani A, Nissen P. 2006. Elongation factor Tu-targeted antibiotics: Four different structures, two mechanisms of action. FEBS Lett 580: 4576-4581.

Reeves DS. 1987. The pharmacokinetics of fusidic acid. $J$ Antimicrob Chemother 20: 467-476.

Sachdeva M, Leeds JA. 2015. Subinhibitory concentrations of LFF571 reduce toxin production by Clostridium difficile. Antimicrob Agents Chemother 59: 1252-1257.

Sears P, Crook DW, Louie TJ, Miller MA, Weiss K. 2012. Fidaxomicin attains high fecal concentrations with minimal plasma concentrations following oral administration in patients with Clostridium difficile infection. Clin Infect Dis 55: S116-S120.

Seddon JBF, Sears P. 2012. Mutant prevention concentration of fidaxomicin for Clostridium difficile. In 52nd Interscience Conference on Antimicrobial Agents and Chemotherapy. San Francisco, CA.

Seddon JBF, Gomez A, Artsimovitch I, Sears P. 2011. RNA polymerase target modification in Clostridium difficile with reduced susceptibility to fidaxomicin. In 51st Interscience Conference on Antimicrobial Agents and Chemotherapy. Chicago, IL.

Sela S, Yogev D, Razin S, Bercovier H. 1989. Duplication of the tuf gene: A new insight into the phylogeny of eubacteria. J Bacteriol 171: 581-584.

Selva E, Beretta G, Montanini N, Saddler GS, Gastaldo L, Ferrari P, Lorenzetti R, Landini P, Ripamonti F, Goldstein BP, et al. 1991. Antibiotic GE2270 a: A novel inhibitor of bacterial protein synthesis. I: Isolation and characterization. J Antibiot (Tokyo) 44: 693-701.

Selva E, Montanini N, Stella S, Soffientini A, Gastaldo L, Denaro M. 1997. Targeted screening for elongation factor Tu binding antibiotics. J Antibiot (Tokyo) 50: 22-26.

Sergio S, Pirali G, White R, Parenti F. 1975. Lipiarmycin, a new antibiotic from Actinoplanes. III: Mechanism of action. J Antibiot (Tokyo) 28: 543-549.

Sonenshein AL, Alexander HB, Rothstein DM, Fisher SH. 1977. Lipiarmycin-resistant ribonucleic acid polymerase mutants of Bacillus subtilis. J Bacteriol 132: 73-79.

Srivastava A, Talaue M, Liu S, Degen D, Ebright RY, Sineva E, Chakraborty A, Druzhinin SY, Chatterjee S, Mukhopad- 
J.A. Leeds

hyay J, et al. 2011. New target for inhibition of bacterial RNA polymerase: "Switch region." Curr Opin Microbiol 14: $532-543$.

Stark H, Rodnina MV, Rinke-Appel J, Brimacombe R, Wintermeyer W, van Heel M. 1997. Visualization of elongation factor Tu on the Escherichia coli ribosome. Nature 389: 403-406.

Surawicz CM, Brandt LJ, Binion DG, Ananthakrishnan AN, Curry SR, Gilligan PH, McFarland LV, Mellow M, Zuckerbraun BS. 2013. Guidelines for diagnosis, treatment, and prevention of Clostridium difficile infections. Am J Gastroenterol 108: 478-498; quiz 499.

Swanson RN, Hardy DJ, Shipkowitz NL, Hanson CW, Ramer NC, Fernandes PB, Clement JJ. 1991. In vitro and in vivo evaluation of tiacumicins $\mathrm{B}$ and $\mathrm{C}$ against Clostridium difficile. Antimicrob Agents Chemother 35: 1108-1111.

Tavecchia P, Gentili P, Kurz M, Sottani C, Bonfichi R, Lociuro S, Selva E. 1994. Revised structure of the antibiotic GE 2270A. J Antibiot (Tokyo) 47: 1564-1567.

Tavecchia P, Gentili P, Kurz M, Sottani C, Bonfichi R, Selva E, Locurio S, Restelli E, Ciabatti R. 1995. Degradation studies of antibiotic MDL 62,879 (GE2270A) and revision of the structure. Tetrahedron 51: 4867-4890.

Theriault RJ, Karwowski JP, Jackson M, Girolami RL, Sunga GN, Vojtko CM, Coen LJ. 1987. Tiacumicins, a novel complex of 18-membered macrolide antibiotics. I: Tax- onomy, fermentation and antibacterial activity. J Antibiot (Tokyo) 40: 567-574.

Ting LS, Praestgaard J, Grunenberg N, Yang JC, Leeds JA, Pertel P. 2012. A first-in-human, randomized, doubleblind, placebo-controlled, single- and multiple-ascending oral dose study to assess the safety and tolerability of LFF571 in healthy volunteers. Antimicrob Agents Chemother 56: 5946-5951.

Tsutsumi LS, Owusu YB, Hurdle JG, Sun D. 2014. Progress in the discovery of treatments for C. difficile infection: A clinical and medicinal chemistry review. Curr Top Med Chem 14: 152-175.

Voorhees RM, Ramakrishnan V. 2013. Structural basis of the translational elongation cycle. Annu Rev Biochem 82: 203-236.

Yin N, Li J, He Y, Herradura PS, Pearson A, Mesleh MF, Mascio CT, Howland K, Steenbergen J, Thorne GM, et al. 2015. Structure-activity relationship studies of a series of semi-synthetic lipopeptides leading to the discovery of surotomycin, a novel cyclic lipopeptide being developed for the treatment of Clostridium difficile-associated diarrhea. J Med Chem 58: 5137-5142.

Zuurmond AM, Martien de Graaf J, Olsthoorn-Tieleman LN, van Duyl BY, Morhle VG, Jurnak F, Mesters JR, Hilgenfeld R, Kraal B. 2000. GE2270A-resistant mutations in elongation factor $\mathrm{Tu}$ allow productive aminoacyl-tRNA binding to EF-Tu.GTP.GE2270A complexes. J Mol Biol 304: 995-1005. 


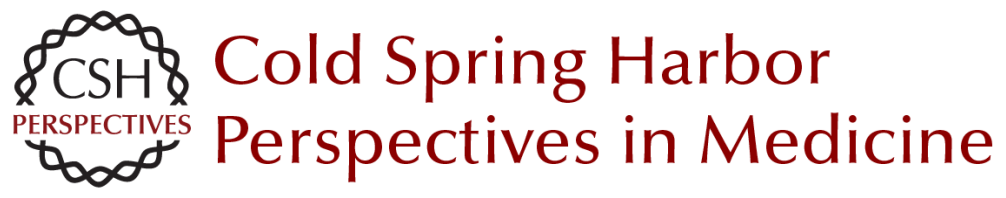

\section{Antibacterials Developed to Target a Single Organism: Mechanisms and Frequencies of Reduced Susceptibility to the Novel Anti- Clostridium difficile Compounds Fidaxomicin and LFF571}

Jennifer A. Leeds

Cold Spring Harb Perspect Med 2016; doi: 10.1101/cshperspect.a025445

Subject Collection Antibiotics and Antibiotic Resistance

Fosfomycin: Mechanism and Resistance Lynn L. Silver

Pleuromutilins: Potent Drugs for Resistant Bugs

--Mode of Action and Resistance Susanne Paukner and Rosemarie Riedl

Appropriate Targets for Antibacterial Drugs Lynn L. Silver

Lincosamides, Streptogramins, Phenicols, and Pleuromutilins: Mode of Action and Mechanisms of Resistance

Stefan Schwarz, Jianzhong Shen, Kristina Kadlec, et al.

Resistance to Macrolide Antibiotics in Public Health Pathogens

Corey Fyfe, Trudy H. Grossman, Kathy Kerstein, et al.

Bacterial Protein Synthesis as a Target for

Antibiotic Inhibition

Stefan Arenz and Daniel N. Wilson

Antibacterial Antifolates: From Development through Resistance to the Next Generation

Alexavier Estrada, Dennis L. Wright and Amy C. Anderson

Antibacterial Drug Discovery Targeting the Lipopolysaccharide Biosynthetic Enzyme LpxC Alice L. Erwin
The Whys and Wherefores of Antibiotic

Resistance

Cameron R. Strachan and Julian Davies

$\beta$-Lactamases: A Focus on Current Challenges Robert A. Bonomo

Approved Glycopeptide Antibacterial Drugs: Mechanism of Action and Resistance Daina Zeng, Dmitri Debabov, Theresa L. Hartsell, et al.

Mechanism of Action and Resistance to Daptomycin in Staphylococcus aureus and Enterococci William R. Miller, Arnold S. Bayer and Cesar A. Arias

Polymyxin: Alternative Mechanisms of Action and Resistance

Michael J. Trimble, Patrik Mlynárcik, Milan Kolár, et al.

Topoisomerase Inhibitors: Fluoroquinolone

Mechanisms of Action and Resistance David C. Hooper and George A. Jacoby

$\beta$-Lactams and $\beta$-Lactamase Inhibitors: An

Overview

Karen Bush and Patricia A. Bradford

Rifamycins, Alone and in Combination David M. Rothstein

For additional articles in this collection, see http://perspectivesinmedicine.cshlp.org/cgi/collection/ 